\title{
Growing up among cultures: intercultural competences, personality, and leadership styles of third culture kids
}

\author{
Monika F. de Waal* and \\ Marise Ph. Born \\ Faculty of Social Sciences, \\ Erasmus University Rotterdam, \\ 3000 DR Rotterdam, The Netherlands \\ Email: monika@uniquesources.nl \\ Email: m.ph.born@essb.eur.nl \\ *Corresponding author
}

\begin{abstract}
The world seems to be increasingly in demand of global leaders with a transformational leadership style who do business across borders with intercultural ease. To identify such leaders, this study explores whether third culture kids (TCKs) $(n=121)$ compared to non-TCKs $(n=116)$ exhibit a stronger set of multicultural personality traits and intercultural competences, and whether TCKs compared to non-TCKs, via their multicultural personality traits and intercultural competences, prefer transformational leadership more. Results from group comparisons indicated that TCKs display more intercultural sensitivity than non-TCKs. Parallel mediated regression analyses showed that being a TCK, compared to not being a TCK, had a positive indirect effect on their preference for transformational leadership through open-mindedness, while it had a negative indirect effect on their preference for transformational leadership through flexibility and emotional stability.
\end{abstract}

Keywords: TCKs; third culture kids; transformational leadership; multicultural personality traits; intercultural competences; growing up in different cultures; mediated regression analysis.

Reference to this paper should be made as follows: de Waal, M.F. and Born, M.Ph. (2020) 'Growing up among cultures: intercultural competences, personality, and leadership styles of third culture kids', European $J$. International Management, Vol. 14, No. 2, pp.327-356.

Biographical notes: Monika F. de Waal, as a PhD candidate at the Faculty of Social Sciences, Erasmus University Rotterdam, combines the path of practitioner with the path of researcher. Her fields of interest are cross-cultural management as well as leadership and organisational development. Her mind and heart are set towards people in organisations and their development, and this is what she contributes as facilitator of personal, professional and organisational processes. In all she is doing, she aims to honour diversity, being a TCK herself.

Marise Ph. Born is Full Professor of Personnel Psychology at the Erasmus University Rotterdam. She furthermore is Endowed Professor of Industrial and Personnel Psychology at the VU University Amsterdam and at Optentia \& the Faculty of Economic and Management Sciences North-West University South Africa. Her research interests are in the domains of personnel selection, crosscultural psychology, test development, and personality and individual differences. 


\section{Introduction}

Globalisation leads to an increasingly diverse working environment, resulting in a growing number of people working in an intercultural and international setting (Matthewman, 2011). In such settings, people are expected to maintain international contacts and deal with colleagues coming from different cultural backgrounds. According to Matveev (2017, p.5), "A new skills set, including intercultural competence, will help managers face the challenges of a complex, dynamic, and competitive business environment". Similarly, Rosen (2000) sees global literacy as the new leadership competence required for business success. Rosen defines being globally literate as "seeing, thinking, acting, and mobilizing in culturally mindful ways" (Rosen, 2000, p.57).

A review by Cumberland et al. (2016) identified no less than 17 personality traits that were linked to effective global leadership, including open-mindedness and flexibility. Besides the importance of multicultural personality traits, the need of intercultural competences for global leadership has been pointed out. Bird et al. (2010), for instance, see intercultural competence as increasingly necessary in a global workplace, arguing that collaborative and coordinating demands are stretching leaders' capacities. Such views have been corroborated by empirical findings. Related to intercultural competences, Caligiuri and Tarique (2009) examined whether a set of situation-specific cross-cultural competences was related to international assignee success (Caligiuri and Tarique, 2009, 2012, 2016). The effectiveness of global leaders' activities was affected by experiences that included high contact cross-cultural leadership development. More generally, they found that significant intercultural experiences in either an individual's professional or personal life positively impacted their flexibility and tolerance for ambiguity.

The question may be asked which individuals possess such multicultural personality traits and intercultural competences. Are these traits and competences more prevalent in people who have had intercultural experiences from an early age onwards, such as third culture kids (TCKs)? TCKs are people who, in the period between 0 and 18 years of age, have lived in another culture than the passport culture of their parents (Pollock and Van Reken, 2009). Many TCKs thus have had unique intercultural experiences in their years of development, growing up among cultures. As Pollock et al. (2010) emphasised, this uniqueness lies in the actual living in different cultural worlds instead of simply watching, studying, or analysing other cultures. Their considerable cultural capital therefore may provide TCKs with an intercultural advantage (Cottrell, 2002). In this regard, researchers have argued that their past experiences and international focus may prepare TCKs, when older, to be well-suited for expatriate assignments, for example intended for multinational business purposes (Bonebright, 2010; Selmer and Lam, 2004). Supporting such reasoning, Miska et al. (2013) found that when working with people from other nationalities, one's intercultural competences of emotional sensitivity and social flexibility positively relate to effective and responsible global leadership.

Global leadership has been described as "the process of influencing the thinking, attitudes, and behaviours of a global community to work together synergistically toward a common vision and common goal" (Bird et al., 2010, p.811). From this we can infer that there is clear similarity with the transformational leadership style, the latter referring to inspiring one's followers to accomplish more, and emanating from the widely used leadership model of Bass et al. (1996). The transformational leadership style has a focus 
on inspiring followers with a vision towards a goal. When placing leadership styles in an intercultural context, conceptually, transformational leadership is closest to global leadership compared to both other styles which Bass et al. (1996) distinguish. These two other styles are transactional leadership, with a focus on matching the needs of the organisation and the needs of the employees, and laissez-faire leadership, a style of absent leadership. Empirical research by Van Woerkom and De Reuver (2009) on leadership styles has shown that within an intercultural work environment, transformational leadership is a particularly effective style to increase subordinates' work performance. Furthermore, Van Woerkom and De Reuver (2009) reported a positive relationship between displaying transformational leadership and all five traits of the multicultural personality model of Van der Zee and Van Oudenhoven (2000), namely cultural empathy, open-mindedness, social initiative, emotional stability and flexibility.

Related to the above lines of thought, in this study we expect TCKs to exhibit a stronger set of multicultural personality traits and intercultural competences than nonTCKs and we investigate how these traits and competences in turn could relate to one's preferred leadership style, in particular transformational leadership. To this end, the following section will deal with the topics of third culture kids, multicultural personality traits and intercultural competences, and finally leadership styles, especially the transformational leadership style. These topics will lead to the formulation of several hypotheses.

\section{Third culture kids and cross cultural kids}

TCKs form a subcategory of the group of Cross Cultural Kids (CCKs; Van Reken and Bethel, 2005). The different types of CCKs are presented in Figure 1. CCKs are children who "lived in - or meaningfully interacted with - two or more cultural environments for a significant period of time during childhood" (Pollock and Van Reken, 2009, p.31). Bicultural as well as multicultural children who have parents originating from two or more cultural backgrounds are a subcategory of CCKs as well. The categories of CCKs among others include children of immigrants and refugees, ethnic minority, and international adoption children (Pollock and Van Reken, 2009). Immigrant children are experiencing another culture as a result of the choice of their parents to permanently move to another country, with the assumption that they will not be returning to their home country. Children of refugees are CCKs living in a country other than their home country as a result of forced circumstances such as war, politics, violence or natural disaster, often with the assumption that they will be returning to their home country. Whereas children of ethnic minority groups are children of parents not belonging to the ethnic majority of the country of residence, international adoption children are children adopted by parents who do not originate from their country of birth.

In Figure 1, third culture kids are labelled as Traditional TCKs. This term refers to children who encounter and live in other cultures because of the career choice of at least one of their parents. The term Adult TCKs is used for adults who grew up as TCKs and is commonly abbreviated as ATCKs. However, more often the abbreviation used is TCKs. The parents' (passport) culture is often known as the home or 'first' culture, and the host culture is labelled as the second culture (Pollock and Van Reken, 2009). Occasionally, TCKs also are referred to as 'global nomads' (McCaig, 1994) as they share the experience of movement, or a lack of fixed territory (Cason, 2015). The shared 
commonalities of TCKs, who are living an internationally mobile lifestyle, often lead to a 'neither/nor world', which is called the Interstitial or Third Culture (Pollock et al., 2010). Thus, TCKs generally feel that they belong only partly, but not fully, to all cultures they have experienced. In adjusting to a wide variety of influences, they might have incorporated elements of the cultures that they grew up in as well as elements of their parents' passport culture. The so-called third culture, however, has been defined as "a generic term to discuss the lifestyle created, shared and learned by those who are from one culture and in the process of relating to another one" (Pollock et al., 2010, p.16).

Living without one's parents in another country during childhood, e.g., having had a boarding school period abroad, does not in itself identify a person as a TCK. Furthermore, to be identified as a TCK it is important that one's cross-cultural experience unfolds before reaching the age of eighteen. According to Cason (2015), "TCKs may be better understood as belonging to a separate culture of 'in-between-ness', or in other words as ex-members of an expatriate subculture, who, in adulthood, are generally excluded from their parents' homeland by virtue of their growing up outside the passport culture of their parent" (Cason, 2015, p.36).

TCKs have been classified into five subgroups, as shown in Figure 2. This classification is based on reasons why parents lived abroad, namely, according to their parents' so-called sponsor organisations: (1) the military, (2) missionary (and nonprofit work), (3) corporate (business), and (4) foreign service (diplomats) and (5) other (Hervey, 2009; Pollock and Van Reken, 2009). Presently, it is commonly recognised that there are many more categories of TCKs, such as parents working for NGOs and parents working in education (Pollock and Van Reken, 2009).

Figure 1 Cross cultural kids (Pollock and Van Reken, 2009). TCKs are labelled as traditional third culture kids in this figure. The figure is used with permission from the authors

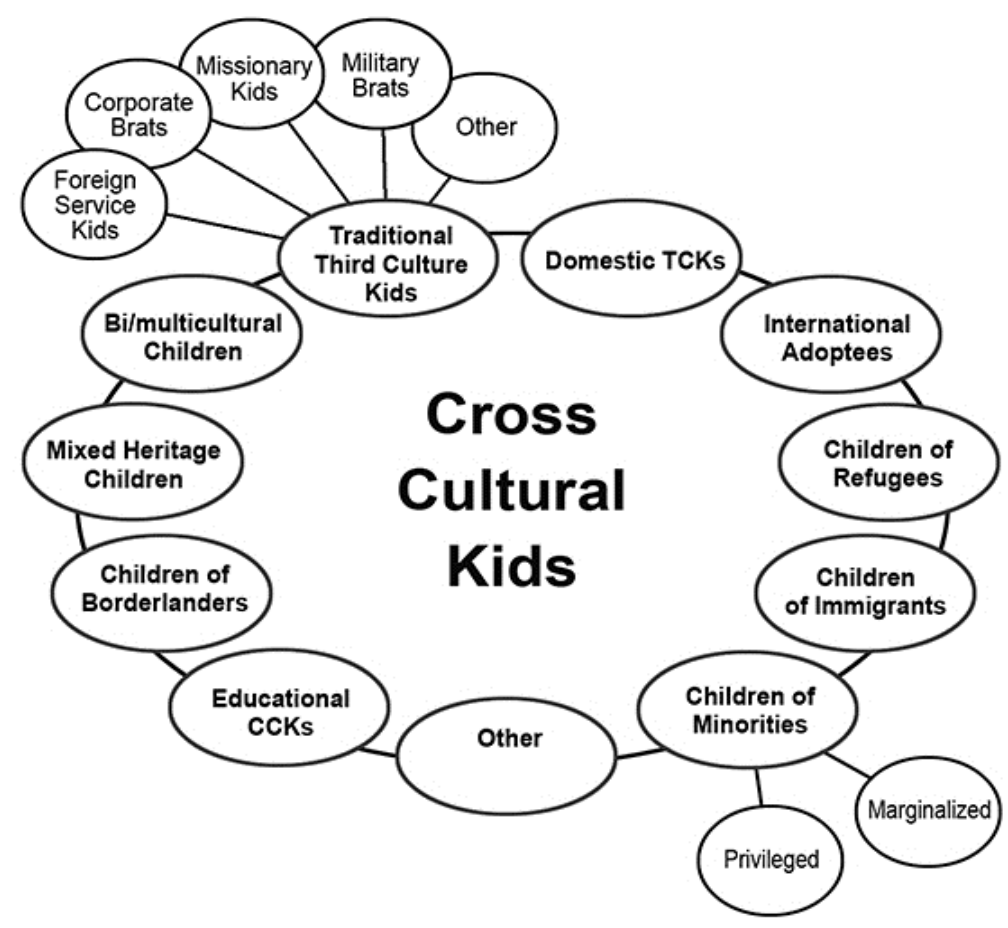


Figure 2 Types of TCKs, labelled as traditional third culture kids (Pollock and Van Reken, 2009). The figure is used with the permission from the authors

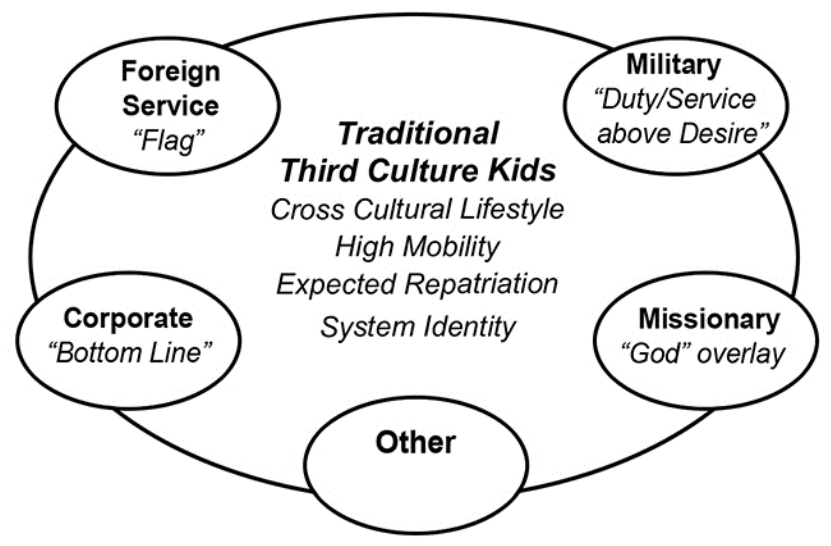

Lam and Selmer (2004) reported that adolescent TCKs had stronger international mobility preferences compared to their non-TCK peers. Additionally, Cottrell (2002) reported that "One of the most noteworthy characteristics of ATCKs is their extraordinary educational achievement; $81 \%$ had at least a bachelor's degree compared to $21 \%$ of the US population over 25 (years of age) at the same time" (Cottrell, 2002, p.235). It should be noted that this research is uniquely based on ATCKs with US passports, thus a generalisation to other ATCKs is yet to be empirically confirmed.

Given that TCKs show a stronger preference for travel and an international career, they often speak several languages. Combined with a reduced preference to settle down, TCKs may be successful as future business expats (Selmer and Lam, 2004). The longer people had lived outside the US as TCKs and the more nations they had lived in, the more likely they were to use another language at work, to have worked outside the US and to have had a work history which was primarily or entirely international (Cottrell, 2002). Such third culture experience is thought to facilitate TCKs in developing a set of intercultural competences (Gerner and Perry, 2000; Lam and Selmer, 2004; Langford, 1998). Their intercultural competences, and likewise, their developed multicultural personality traits may equip them to display better leadership in today's culturally diverse work environment.

Research concerning TCKs has often highlighted the negative effects of their crosscultural experience, such as depression, identity crisis, and experiencing what is known as a 'reverse culture shock' upon returning to their passport country (Fail et al., 2004; Hervey, 2009; Walters and Auton-Cuff, 2009). Several researchers, however, have emphasised that the benefits of their upbringing are unique and far-reaching in a positive sense. For example, McCaig (1994) stated: "In an era when global vision is imperative, where skills in intercultural communication, linguistic ability, mediation, diplomacy and the ability to manage diversity are critical, global nomads are probably better equipped than others" (McCaig, 1994, p.33). The next paragraph will explore the constructs of multicultural personality traits and intercultural competences, including the concept of Cultural Intelligence (CQ), which was introduced in 2002, and their relationship. 


\subsection{Multicultural personality traits, intercultural competences, and cultural intelligence}

Multicultural personality traits (MPTs) as well as intercultural competences (ICs) have been shown to be useful for predicting and explaining individual differences in intercultural effectiveness (Mol et al., 2005; Van Oudenhoven and Van der Zee, 2002; for a review of studies see Matsumoto and Hwang, 2013).

More or less simultaneously, Earley and Ang (2003) introduced the construct of cultural intelligence (CQ), which is also intended to predict individuals' intercultural effectiveness. To date, research on CQ has grown increasingly popular (Fang et al., 2018), as a result of which the need also arises to discuss how MPTs and ICs are conceptually related to CQ. Within CQ, Earley and Ang (2003) distinguish four intercultural facets, namely cognitive CQ (knowledge about cultures), metacognitive CQ (cultural awareness, questioning one's own cultural assumptions), motivational CQ (efforts to understand how to operate effectively cross-culturally) and behavioural CQ (adapting verbal and non-verbal behaviour to another culture). The general concept of CQ has been defined as follows: "A person's capability to adapt effectively to new cultural contexts and thus refers to a form of situated intelligence where intelligently adaptive behaviours are culturally bound to the values and beliefs of a given society or culture" (Earley and Ang, 2003, p.26). In their view, cultural intelligence is partly referred to as cultural meta-cognition, a proposed higher-order faculty enabling individuals to regulate how they use their cultural knowledge and how they adjust their behaviour.

In an extensive review of 142 articles, Fang et al. (2018) categorised two predictors of CQ, personality traits and intercultural experiences, to form antecedents of CQ. Supporting this idea, earlier studies showed that openness for experience was related to all four CQ dimensions mentioned above (Ang and Koh, 2006). Openness for experience can conceptually be related to open-mindedness, one of the identified multicultural personality traits. Furthermore, Remhof et al. (2013) found that individuals' motivational CQ could be predicted from their motivation to explore cultural situations and enjoy new experiences. When traits and competences develop through intercultural experience, one could therefore argue that both multicultural personality traits and intercultural competences may be perceived as CQ antecedents. Having discussed the plausible role of MPTs and ICs as antecedents of CQ, we now discuss MPTs and ICs more in depth.

\subsection{Multicultural personality traits (MPTs)}

Van der Zee and Van Oudenhoven (2000) proposed five multicultural personality dimensions, later referred to as traits (Van der Zee et al., 2013), which are viewed as relevant to intercultural effectiveness. These five traits are: cultural empathy (defined as the degree to which a person can empathise with thoughts, feelings, and behaviours of individuals from a different culture), flexibility (the ability to navigate new and unexpected cross-cultural situations), social initiative (the tendency to approach new social situations actively), open-mindedness (the extent to which one holds an open and unbiased attitude towards people from a different culture), and emotional stability (the ability to regulate emotional responses in cross-cultural stressful situations) (Van der Zee et al., 2013). 
Traditionally, aspects of an individual's personality are considered to be more or less stable, whereas competences are considered to be malleable (Roberts and DelVecchio, 2006). In the MPT framework, flexibility and emotional stability are assumed to be fairly stable, whereas cultural empathy, social initiative and open-mindedness are considered to be more amenable to change (Herfst et al., 2008). Likewise, other studies indicate that the MPTs may be changeable. Van Bakel (2012) and Van Bakel et al. (2014), for example, found that expatriates' open-mindedness changed depending on contact with locals: Expatriates in the Netherlands with little contact with locals became less openminded after nine months abroad, whereas those with systematic contact remained as open-minded as at the beginning of their stay, provided they also had a long-term personal relationship.

Findings reported by Dewaele and Van Oudenhoven (2009) comparing TCKs and non-TCKs on multicultural personality traits are of interest to the current study. They found that TCKs on average scored higher than non-TCKs on cultural empathy and openmindedness, but lower on emotional stability. They, however, found that TCKs did not score significantly differently from non-TCKs on flexibility or social initiative. The participant sample consisted of 79 respondents between the age of 13 to 15 of which $50 \%$ were TCKs and 50\% were non-TCKs. The authors explained their findings by stating that acculturation is a stressful process that may reduce one's emotional stability, whereas the pressure to fit in and deal with different languages and cultures might strengthen one's cultural empathy and open-mindedness.

Based on the findings presented above, we expect that three traits, notably cultural empathy, open-mindedness and emotional stability from the MPT framework are changeable by external factors, and hence, that TCKs on average may score differently on these multicultural personality traits than non-TCKs due to their early cross-cultural life experiences. Emotional stability is included here since living across different cultures impacts stability, especially in comparison to not moving during developmental years. With this knowledge, we aim to investigate whether their findings are generalisable to TCKs as adults. As a consequence, hypothesis 1 was formulated as follows:

Hypothesis 1: TCKs will score significantly higher than non-TCKs on cultural empathy (1a), and on open-mindedness (1b), but significantly lower than non-TCKs on emotional stability (1c).

\subsection{Intercultural competences (ICs)}

Intercultural competences are regarded as sets of knowledge, skills, attitudes and other characteristics assumed to contribute to effective intercultural interaction (Engle et al., 2001; Miska et al., 2013; Ruben, 1989; Ruben and Kealey, 1979; Spitzberg and Changnon, 2009; Thomas and Fitzsimmons, 2008). The search for intercultural competences to explain, predict and assess differences in how individuals deal with intercultural interactions started with a series of Peace Corps studies in the 1960s (Smith, 1966). Since then, numerous intercultural competences have been proposed (cf. Spitzberg and Changnon, 2009, for a list of more than 300 competences), and different underlying competence models have been discerned (Matveev and Merz, 2014; Spitzberg and Changnon, 2009; Thomas and Fitzsimmons, 2008).

One of the models used to assess intercultural competences is the Intercultural Readiness model, measuring competences with the Intercultural Readiness Check (IRC; 
Van der Zee and Brinkmann, 2004). The model regards the IRC competences as prerequisites for intercultural effectiveness. The four competences discerned by the Intercultural Readiness model are the following: intercultural sensitivity (the ability to take an active interest in others, their cultural background, needs and perspectives), intercultural communication (the ability to monitor and adjust one's own communicative behaviours when communicating with culturally different others), building commitment (the ability to influence one's social environment, based on a concern for integrating different perspectives), and managing uncertainty (the degree to which one appreciates the uncertainty of culturally diverse environments as an opportunity for personal development) (Brinkmann and Van Weerdenburg, 2014; Van der Zee and Brinkmann, 2004).

With respect to how the four competences are related to one another, the Intercultural Readiness model makes no specific assumptions. This framework views all competences are learnable and trainable. In terms of Thomas and Fitzsimmons' typology of models, the IRC can be classified as a 'developmental and learning model' (Thomas and Fitzsimmons, 2008). These authors consider intercultural sensitivity to be an information skill, intercultural communication and building commitment as interpersonal skills, and managing uncertainty as an action skill.

Van der Zee and Brinkmann (2004) have shown empirically that the intercultural competences (ICs) are predictive of employees' international career aspirations and that they are related to previous experience abroad. Van der Poel (2016) reported that the ICs were predictive of students' intercultural development during a stay abroad. Furthermore, Lyubovnikova et al. (2015) found that intercultural sensitivity as measured by the IRC predicted the degree to which students appreciated their group's cultural diversity as a resource for learning and performance.

A survey by Williams (2005) showed that even a short exposure to different cultures improved intercultural competences. Over a period of four months, students participating in an exchange program showed significantly more intercultural skills than those who did not. Anderson et al. (2006) confirmed these findings when investigating an exchange period of four weeks, and Pedersen (2010) confirmed similar findings in a study on the development of intercultural sensitivity over a year. Furthermore, previous research has shown that being exposed to different cultures, particularly long exposures, improves these competences and intercultural skills (Anderson et al., 2006; Pedersen, 2010; Williams, 2005). Consequently, we aim to investigate whether these findings can be expanded to TCKs, formulating the second hypothesis as follows:

Hypothesis 2: TCKs score significantly higher than non-TCKs on intercultural sensitivity (2a), intercultural communication (2b), building commitment (2c), and managing uncertainty (2d).

\subsection{Transformational leadership}

With a better understanding of multicultural personality traits and intercultural competences and how these are related to being a TCK, we explore the relationship between these traits and competences and transformational leadership. Subsequently, the relationship between TCK status and transformational leadership through these traits and competences will be focussed upon. 
In an investigation of over two-hundred global leaders, Caligiuri and Tarique (2009) found that cross-cultural leadership development activities as well as leaders' personality characteristics were predictors of effective global leadership. For example, they found that extraversion, a personality characteristic, moderated the relationship positively between high contact cross-cultural leadership development activities and effectiveness on global leadership activities (Caligiuri and Tarique, 2009).

Transformational leadership was coined by Burns (1978) and defined as "leaders inducing followers to act for certain goals that represent the values and the motivations the wants, and needs, the aspirations and expectations - of both leaders and followers" (Burns, 1978, p.19). The influence of multicultural personality on one's own transformational leadership and performance was measured among 138 managers in the earlier mentioned study of Van Woerkom and De Reuver (2009) through self-reported behaviour and self-reported preferences. The intercultural context in which these managers worked included expatriate assignments as well as roles in which they needed to lead multicultural groups. Results showed a positive relationship between all five traits of cultural empathy, flexibility, social initiative, open-mindedness, and emotional stability with transformational leadership.

With regards to these findings, we aim to replicate the findings of Van Woerkom and De Reuver (2009) and therefore formulated the third hypothesis as follows:

Hypothesis 3: The multicultural personality traits of cultural empathy (3a), flexibility (3b), social initiative (3c), open-mindedness (3d), and emotional stability (3e) correlate positively with a preference to display transformational leadership.

Next to the expected relationship between multicultural personality traits and transformational leadership, we may expect relationships between intercultural competences and transformational leadership. Looking at the aspect of transformational leadership, research often refers to effective global leadership. This latter type of leadership combines ways to integrate thoughts, attitudes and behaviours to be able to reach common visions and goals through working together (Bird et al., 2010), and leads to the concept of a global mind-set (Cohen, 2007). In their review of the literature on a global mind-set, Levy et al. (2007) defined this construct as "a highly complex cognitive structure characterized by an openness and articulation of multiple cultural and strategic realities on both global and local levels, and the cognitive ability to mediate and integrate across the multiplicity" (Levy et al., 2007, p.244). The global mind-set links the intercultural competences, as defined previously as sets of knowledge, skills, attitudes and other characteristics, to the vision and strategic emphasis of transformational leadership.

Transformational leaders will need good verbal and non-verbal communication skills in an intercultural context to be able to develop a vision and work towards a vision together with one's diverse subordinates. Leaders in an intercultural context aim to inspire their followers towards a common vision, and can be expected to be resilient, to withstand stress, have excellent verbal and non-verbal communication, and have a high tolerance for ambiguity, frustration and uncertainty (Verghese and D'Netto, 2011). This tolerance (for ambiguity, frustration and uncertainty) is recognised in the intercultural competence of managing uncertainty, as described by Brinkmann and Van Weerdenburg (2014), which comprises the facets of openness to cultural diversity as well as exploring 
new approaches. Relatedly, Verghese and D'Netto mentioned the need for more research on the relationship between global leadership and cultural intelligence (Verghese and D'Netto, 2011). The meta-analytic review of CQ and its dimensions by Schlaegel et al. (2017) also concluded that transformational leadership was positively and significantly related to overall CQ as well as to the separate CQ dimensions. These expectations for leaders can be recognised in competences such as intercultural sensitivity and crosscultural competence (Bücker and Poutsma, 2010). Intercultural sensitivity, according to Brinkmann and Van Weerdenburg (2014) includes cultural awareness and attention to signals.

Regarding the four intercultural competences that the Intercultural Readiness model recognises, we formulated hypothesis 4 . This hypothesis investigates the relationship between competences and transformational leadership and is formulated as follows:

Hypothesis 4: Intercultural sensitivity (4a), intercultural communication (4b), building commitment (4c), and managing uncertainty (4d), correlate positively with a preference to display transformational leadership.

The integration of all hypotheses offered until now leads us to an integrated research expectation: Do TCKs, compared to non-TCKs, more strongly prefer to show transformational leadership?

Such a relationship would imply that the international and intercultural experience during one's formative years might lead to a preference for displaying transformational leadership. For example, Useem and Downie (1976) and Useem et al. (1963) were among the first to recognise that TCKs have developed cultural insights that broaden their worldview and increase their tolerance for diversity. Having the cultural insights and tolerance for diversity may allow someone to want to exercise, and recognise the benefits of transformational leadership. Such a direct relationship between TCK status and transformational leadership would signify that TCKs, compared to non-TCKs, have a higher preference to show transformational leadership, as a result of their growing up cross culturally in different countries before the age of 18 years.

Both TCKs and non-TCKs can develop multicultural personality traits and intercultural competences, during their growing up. However, as mentioned before (Van Bakel, 2012), for TCKs, one's open-mindedness is expected to increase, based on contact with a host-culture. Therefore, examining the mediated relationship between TCK-status and transformational leadership through such traits and competences is also important. In other words, an effect of being a TCK, compared to not being a TCK, on one's multicultural personality traits and intercultural competences could in turn have an effect on one's preference for transformational leadership. That is, a higher preference of transformational leadership among TCKs compared to non-TCKS may not be the result of one's intercultural experience directly, but rather the result of one's intercultural experiences augmenting and developing certain skills and traits. Thus, hypothesis 5 is formulated as follows:

Hypothesis 5: There is a significant relationship between TCK status and transformational leadership as preferred leadership style, either directly (5a) or mediated by multicultural personality traits (MPTs) (5b), and intercultural competences (ICs) (5c). 
Figure 3 Proposed hypotheses about the relationship between TCK status $(0=$ non-TCK, $1=\mathrm{TCK})$ and transformational leadership, either directly or mediated by intercultural competences and multicultural personality traits

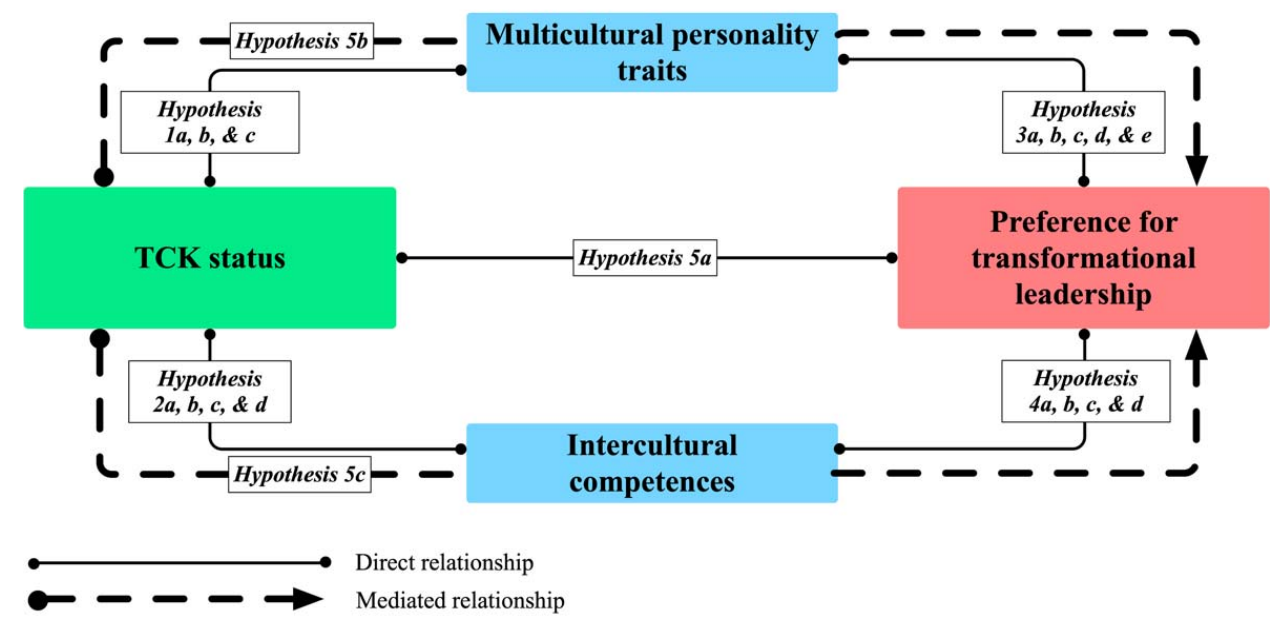

\section{Method}

\subsection{Participants and procedure}

In order to achieve diversity in the response group, we used our direct access to potential Dutch military TCKs as one of the four types of traditional TCKs (see Figure 2) as well as recruitment through third culture kids' Facebook forums (e.g., 'TCKid') and through personal networks.

Regarding the sample size, we aimed to detect a minimum mean difference between TCKs and non-TCKs in multicultural personality traits and intercultural competences, that would represent a value of Cohen's $d=.4$. This is considered the lower bound of a medium effect size (Cohen, 1988, p.40), with power $1-\beta=.80$ at level $\alpha=.05$ (i.e., the $p$-value must be $\leq .05$ ). Based on these conditions, we calculated a minimum sample size of $n=100$ per TCK and non-TCK group respectively using the software G*Power (Faul et al., 2007). Therefore, data collection was stopped soon after this sample size was reached in both groups.

The 237 participants were between the ages of 19 and 74 years and had a mean age of $M=42.3$ years $(S D=13.2)$. The sample consisted of $46.0 \%$ male participants $(n=109)$ and $54.0 \%$ female participants $(n=128)$. Overall, $51.1 \%(n=121)$ were TCKs, and $48.9 \%(n=116)$ were non-TCKs. Within the group of TCKs the mean age was $M=41.4$ years $(S D=13.7)$ while the non-TCKs had a mean age of $M=43.2$ years $(S D=12.7)$. Demographics of the sample are shown in Table 1.

One hundred and thirteen participants reported being in a leadership position with subordinates, compared to 120 participants reporting not to be working with subordinates. Information was missing from four cases. Within the groups of TCKs and non-TCKs the distribution of having subordinates was comparable: the number of TCKs with subordinates equalled $n=53$, non-TCKs with subordinates equalled $n=60$, TCKs 
without subordinates equalled $n=67$, and non-TCKs without subordinates equalled $n=53$. Also, between TCKs and non-TCKs the number of military respondents versus non-military respondents was balanced: 97 respondents from the military respondents versus 140 non-military respondents participated, while the number of military TCKs was $n=47$, and military non-TCK equalled $n=50$. The number of civilian TCKs was $n=74$, and the number of civilian non-TCKs equalled $n=66$.

Within the total sample, a majority of participants $(70.9 \% ; n=168)$ held a Dutch passport. Among the groups of TCKs and non-TCKs the distribution of Dutch passports and other passports was comparable: the number of TCKs holding Dutch passports equalled $n=85$, and the number of non-TCKs holding Dutch passports equalled $n=83$. Overall, 42 nationalities were represented.

A statistical analysis regarding any differences between TCKs and non-TCKs on demographic variables revealed that they differed significantly on gender $\left(\chi^{2}(235)=\right.$ $-3.09, p=0.002)$. While $36.4 \%(n=44)$ of the TCKs were male, within the non-TCK subgroup this percentage equalled $56.0 \%(n=65)$. Also, the two groups differed with respect to having 'lived abroad for work' (in their adult life) $\left(\chi^{2}(234)=2.36, p=0.019\right)$, with relatively more non-TCKs $(47.4 \%, n=55)$ than TCKs $(32.5 \%, n=39)$ having lived abroad for work. Accordingly, in subsequent analyses, we controlled for these two variables.

All participants filled in an online survey, which was created using Qualtrics. The survey consisted of the following parts respectively (see for details the measures section): firstly, the demographics, secondly, the MPTs (measured with the MPQ), thirdly, the ICs (measured with the IRC) and fourthly, transformational, transactional and laissez-faire leadership style preference (measured with the Multifactor Leadership Questionnaire (MLQ)). The survey contained self-rating scales and open-ended questions. Some openended questions were not used in the present study. An example of such a non-used question, specifically for respondents that had identified themselves as TCKs, is: "Can you describe the degree of interaction with the host culture (s)?" The MPTs and leadership scales could be filled out in Dutch or in English, and the ICs could be filled out in a variety of languages. Most participants completed the IC scale in Dutch $(n=134)$ or English $(n=96)$ but there also were participants who completed this scale in German $(n=1)$, French $(n=3)$, Spanish $(n=2)$ or Japanese $(n=1)$.

Table 1 Demographics of the sample (total $n=237$ )

\begin{tabular}{llcc}
\hline & & $M$ & $S D$ \\
\hline \multirow{2}{*}{ Age in years } & TCK & 41.4 & 13.7 \\
& Non-TCK & 43.2 & 12.7 \\
\hline \multirow{4}{*}{ TCK } & & $n$ & $\%$ \\
& No & 116 & 48.9 \\
\hline \multirow{4}{*}{ Subordinates } & Yes & 121 & 51.1 \\
\hline & No & 120 & 50.6 \\
& TCK & 67 & \\
& Non-TCK & 53 & 47.7 \\
& Yes & 113 & \\
\hline
\end{tabular}


Table 1 Demographics of the sample (total $n=237$ ) (continued)

\begin{tabular}{|c|c|c|c|}
\hline & & $n$ & $\%$ \\
\hline \multirow{6}{*}{ Military/Civilian } & Military & 97 & 40.9 \\
\hline & TCK & 47 & \\
\hline & Non-TCK & 50 & \\
\hline & Civilian & 140 & 59.1 \\
\hline & TCK & 74 & \\
\hline & Non-TCK & 66 & \\
\hline \multirow{6}{*}{ Gender } & Male & 109 & 46.0 \\
\hline & TCK & 44 & \\
\hline & Non-TCK & 65 & \\
\hline & Female & 128 & 54.0 \\
\hline & TCK & 77 & \\
\hline & Non-TCK & 51 & \\
\hline \multirow{6}{*}{ Lived abroad for work } & No & 142 & 59.9 \\
\hline & TCK & 81 & \\
\hline & Non-TCK & 61 & \\
\hline & Yes & 94 & 39.7 \\
\hline & TCK & 39 & \\
\hline & Non-TCK & 55 & \\
\hline \multirow{6}{*}{ Travelled abroad for work } & No & 111 & 46.8 \\
\hline & TCK & 55 & \\
\hline & Non-TCK & 56 & \\
\hline & Yes & 122 & 51.5 \\
\hline & TCK & 62 & \\
\hline & Non-TCK & 60 & \\
\hline \multirow{12}{*}{ Highest educational degree } & Middle & 15 & 6.3 \\
\hline & TCK & 6 & \\
\hline & Non-TCK & 9 & \\
\hline & Higher & 78 & 32.9 \\
\hline & TCK & 38 & \\
\hline & Non-TCK & 40 & \\
\hline & University degree & 119 & 50.2 \\
\hline & TCK & 67 & \\
\hline & Non-TCK & 52 & \\
\hline & Other & 20 & 8.4 \\
\hline & TCK & 8 & \\
\hline & Non-TCK & 12 & \\
\hline
\end{tabular}




\section{Measures}

\subsection{TCK status}

One item was used to measure participants' status as a TCK or a non-TCK. This item was the following: 'Have you lived in a country other than your country of birth for a minimum period of one year, with your parents, before reaching the age of 18?' Participants were classified as TCK (coded as 1) if they responded "yes", and non-TCK (coded as 0 ) if they responded "no".

\subsection{Demographics}

Having subordinates, being military or civilian, gender, lived abroad for work, travelled abroad for work, and highest educational degree, were all measured (see Table 1). Furthermore, age, nationality, and parents' nationality, were measured. TCKs were additionally asked about the number of countries of residence between the age of 0 to 18 years, their parents' reasons for moving abroad, as well as the type and degree of interaction with the host culture(s).

\subsection{Multicultural personality traits, intercultural competences and preferred leadership styles}

The Multicultural Personality Questionnaire (Van der Zee et al., 2013) consists of five multicultural personality traits. The MPQ Short Form 40 (Van der Zee et al., 2013) was used in the present study, including the five scales for cultural empathy, flexibility, social initiative, open-mindedness, and emotional stability.

Intercultural competences (ICs) were assessed with the Intercultural Readiness Check (IRC; Van der Zee and Brinkmann, 2004). The IRC is a 57-item questionnaire (Van der Zee and Brinkmann, 2004; Brinkmann and Van Weerdenburg, 2014). The revised version of the IRC (of 2007) was used in the present study. This measures four intercultural competences: intercultural sensitivity, intercultural communication, building commitment, and managing uncertainty (Van der Zee and Brinkmann, 2004).

The Multifactor Leadership Questionnaire (MLQ) measures the degree to which the participant shows a preference to engage in transformational (TFL), transactional (TAL) and laissez-faire (LFL) leadership styles. There are two versions of the MLQ, one relying on self-reports (Leader/Self-form), the other on peer-reports (Leader/Rater-form). For the current study, the Leader/Self-form was used. This version consists of 28 items scored on a five-point scale ranging from "not at all" (1) to "frequently, if not always" (5).

Further details on these measurement instruments, including quality criteria and example items, are provided in Appendix 1.

\subsection{Statistical procedure}

The analysis was carried out using the statistical software IBM SPSS 24. To investigate the relationship of multicultural personality traits and intercultural competences with leadership styles, we calculated partial correlations between these variables, in which we controlled for 'gender' and 'lived abroad for work', due to the dissimilar distribution of 
scores between TCKs and non-TCKs (hypothesis 1, 2, 5a). Additionally, we performed several one-way ANCOVAs to investigate whether TCKs and non-TCKs differed in their level of multicultural personality traits and intercultural competences (hypothesis 1 and 2). Here, TCK status was included as an independent variable, while the variables 'gender' and 'lived abroad for work' were included as covariates.

Mediation analyses to test the indirect relationship of the TCK status on the preferred shown leadership style were executed by using model 4 of the SPSS macro 'Process for SPSS v. 2.16' as designed by Hayes (2016). PROCESS can use both dichotomous and interval data as independent and mediation variables (Hayes, 2012). Here, TCK status was treated as the independent variable and the three leadership styles as the dependent variable in separate analyses. Previous literature argued that for a mediation effect to occur, it is not necessary that the independent and dependent variable show a direct total effect, as suppressor effects might blur this relationship (Field, 2009).

To test hypothesis $5 \mathrm{~b}$ we combined the MPTs as mediators in a parallel mediation model, and to test hypothesis $5 \mathrm{c}$ we combined the ICs as mediators in a separate parallel mediation model. This resulted in a total of 6 models. Considering that all statistical tests relied on a normal distribution as well as the absence of outliers, beforehand we checked the available data for both assumptions. In all variables, but cultural empathy, openmindedness, and transformational leadership, the assumption of normality was met. We normalised those variables that deviated from normality and compared the results to those using the original variables. As there were no major differences in the results, we continued working with the variables without transformation (details are available from the authors).

\section{Results}

Hypothesis 1 stated that TCKs would score significantly higher on cultural empathy and open-mindedness than non-TCKs, but lower on emotional stability. Table 2 shows the intercorrelations (corrected for gender and lived abroad for work), means and standard deviations for all variables. ${ }^{1}$ We performed separate ANCOVAs with cultural empathy, open-mindedness and emotional stability as dependent variables, TCK status as an independent variable, and gender and lived abroad for work as covariates (see Table 3 for the results). Taking into account covariates, the TCKs and non-TCKs did not differ in their level of cultural empathy, open-mindedness or emotional stability; therefore hypothesis $1 \mathrm{a}, 1 \mathrm{~b}$ and $1 \mathrm{c}$ could not be confirmed.

It should be noted that the difference between TCKs and non-TCKs in their open-mindedness and emotional stability was not, albeit nearly, significant; these differences were representative of a small effect as indicated by a Cohen's $d$ value larger than .20 and smaller than, or equal to .30 . On average, TCKs tended to be somewhat higher on open-mindedness, while they scored somewhat lower on emotional stability. There is a possibility that the covariates included obscured the effect of the TCK status on both dependent variables. For example, when the covariates were excluded from the model, the level of emotional stability differed significantly between TCKs and nonTCKs, $F(1,235)=8.93, p=.003$, Cohen's $d=.39$. 
Hypothesis 2 stated that TCKs would score significantly higher than non-TCKs on intercultural sensitivity (2a) and intercultural communication ( $2 \mathrm{~b}$ ), building commitment (2c) and managing uncertainty (2d). We performed one-way ANCOVAs for each dependent variable with TCK status as the independent variable, and 'gender' and 'lived abroad for work' as covariates (Table 2). Comparing TCKs with non-TCKs showed that TCKs scored significantly higher on intercultural sensitivity, while the scores on intercultural communication, building commitment, and managing uncertainty were not significantly different. Accordingly, hypothesis 2a was partially supported, with TCKs showing more intercultural sensitivity.

The effect of being a TCK on intercultural sensitivity represented a moderate effect size (Cohen's $d>.30$ ), while its effect on intercultural communication, building commitment, and managing uncertainty represented small or very small effects ( $.30 \geq$ Cohen's $d>.20$ or Cohen's $d<.20$ respectively)

Table 2 Descriptive statistics and ANCOVA results testing Hypothesis $1 \& 2$, as well as 5a

\begin{tabular}{|c|c|c|c|c|c|}
\hline Hypothesis 1 & $\begin{array}{c}M(S D) \\
T C K\end{array}$ & $\begin{array}{c}M(S D) \\
\text { non-TCK }\end{array}$ & $F(1,232)$ & $p$ & Cohen's d \\
\hline Cultural empathy & $4.14(.57)$ & $4.10(.46)$ & .010 & .750 & $<.03$ \\
\hline Open-mindedness & $4.01(.55)$ & $3.92(.50)$ & 3.76 & .054 & .26 \\
\hline Emotional stability & $3.43(.69)$ & $3.71(.70)$ & 2.86 & .092 & .22 \\
\hline Hypothesis 2 & $\begin{array}{c}M(S D) \\
T C K\end{array}$ & $\begin{array}{c}M(S D) \\
\text { non-TCK }\end{array}$ & $F(1,232)$ & $p$ & Cohen's $d$ \\
\hline Intercultural sensitivity & $6.08(1.86)$ & $5.39(2.03)$ & 5.86 & .016 & .32 \\
\hline $\begin{array}{l}\text { Intercultural } \\
\text { communication }\end{array}$ & $5.98(1.78)$ & $5.66(1.96)$ & 2.39 & .123 & .20 \\
\hline Building commitment & $5.49(2.16)$ & $5.51(2.02)$ & 0.35 & .552 & .09 \\
\hline Managing Uncertainty & $5.23(2.04)$ & $5.22(2.33)$ & 0.39 & .535 & .09 \\
\hline Hypothesis $5 a$ & $\begin{array}{c}M(S D) \\
T C K\end{array}$ & $\begin{array}{c}M(S D) \\
\text { non-TCK }\end{array}$ & $F(1,232)$ & $p$ & Cohen's $d$ \\
\hline $\begin{array}{l}\text { Transformational } \\
\text { leadership }\end{array}$ & $3.76(.64)$ & $3.91(.57)$ & 1.92 & .167 & .18 \\
\hline
\end{tabular}

Hypothesis 3 stated that for all participants, cultural empathy (3a), flexibility (3b), social initiative (3c), open-mindedness (3d), and emotional stability (3e) would correlate positively with their preference to show transformational leadership. This hypothesis was confirmed to a large extent (Table 3). Cultural empathy $(r=.39, p<.001)$, social initiative $(r=.39, p<.001)$, open-mindedness $(r=.42, p<.001)$, and emotional stability $(r=.26, p<.001)$ correlated positively with transformational leadership. However, flexibility $(r=-.06, p=.367)$ did not correlate significantly with transformational leadership. In other words, all participants, TCKs as well as non-TCKs, who scored higher on all of the MPTs except flexibility, tended to show a higher preference to display transformational leadership style. This hypothesis was mostly confirmed. 
Table 3 Intercorrelations (corrected for gender and lived abroad for work), means $(m)$ and standard deviations $(s d)$ for all variables

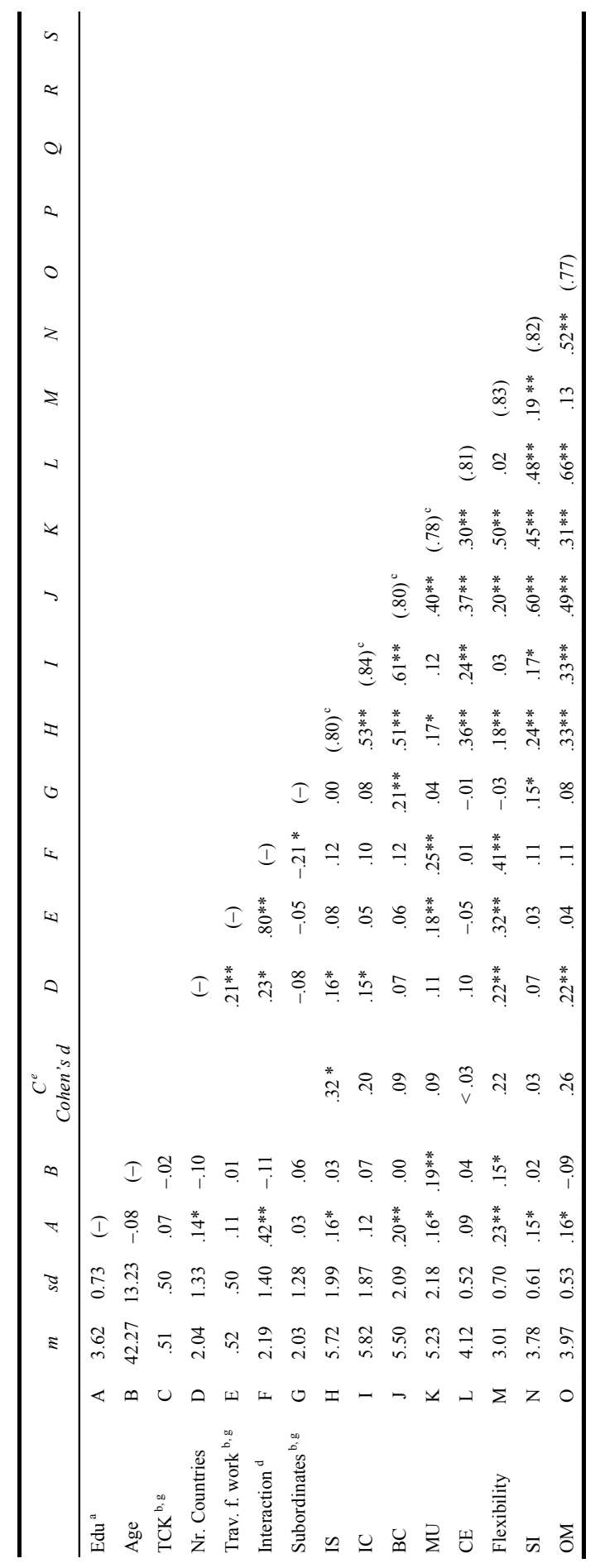


Table 3 Intercorrelations (corrected for gender and lived abroad for work), means $(m)$ and standard deviations $(s d)$ for all variables (continued)

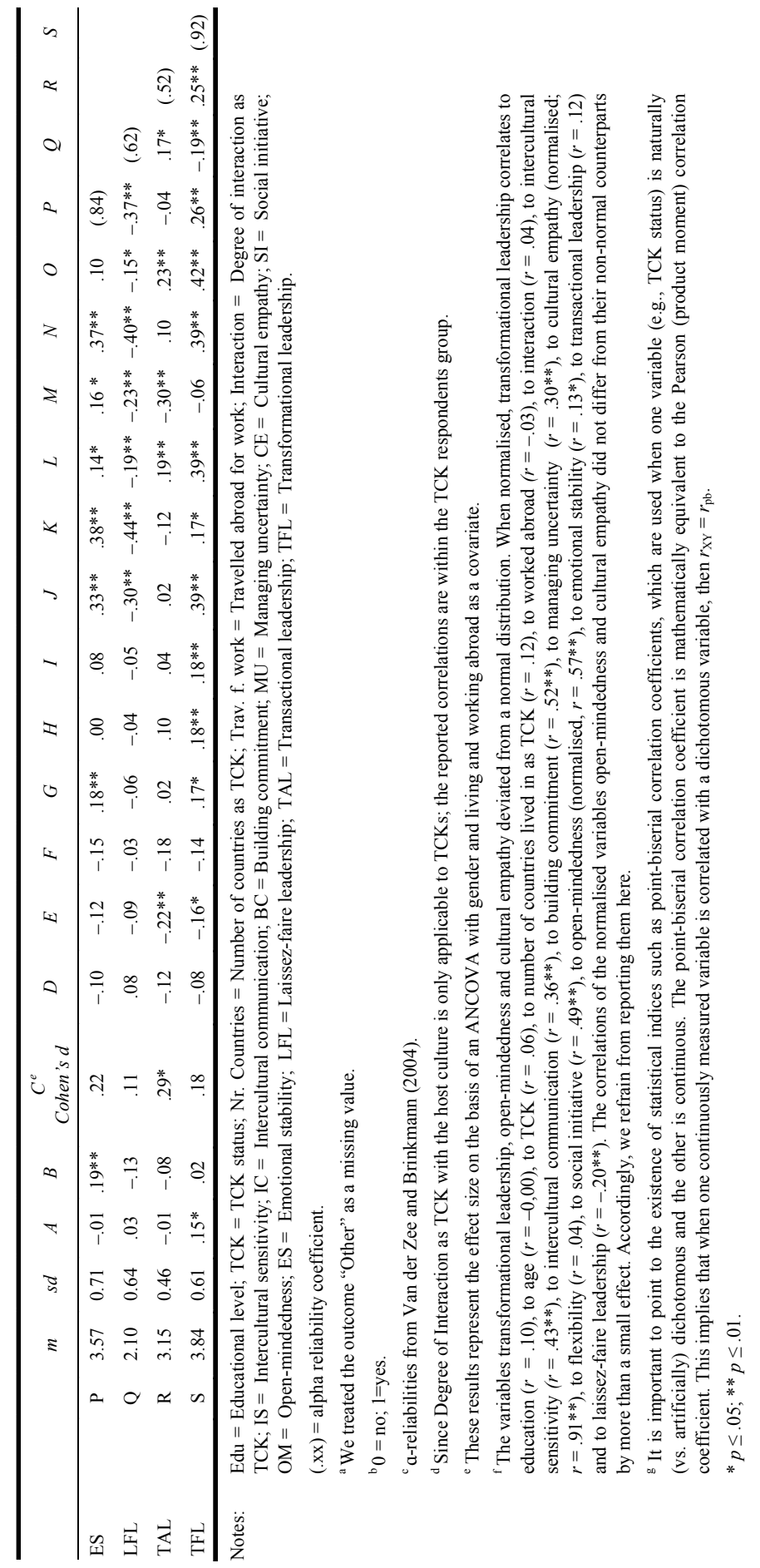


The relationships of cultural empathy, social initiative, and open-mindedness with transformational leadership represented a moderate effect size. On the other hand, the relationships of emotional stability and flexibility with transformational leadership represented a small and very small effect respectively.

Hypothesis 4 stated that for all participants, the four intercultural competences of intercultural sensitivity (4a), intercultural communication (4b), building commitment (4c), and managing uncertainty (4d), would correlate positively with a preference to display transformational leadership. Our findings supported all aspects of this hypothesis. Intercultural sensitivity $(r=.18, p=.008)$, intercultural communication $(r=.18$, $p=.008)$, building commitment $(r=.39, p<.001)$, and managing uncertainty $(r=.17$, $p<.016)$ each correlated positively to transformational leadership. Stated differently, those who scored higher on any of the ICs, tended to show a stronger preference for the transformational leadership style.

The relationship between building commitment and transformational leadership represented a moderate effect size. The other specified relationships represented a small effect size.

Hypothesis 5 stated that there would be a relationship between TCK status and transformational leadership as one's own preferred style of leadership, either directly (5a) or mediated by multicultural personality traits $(5 \mathrm{~b})$ and intercultural competences $(5 \mathrm{c})$. Results for hypothesis $5 \mathrm{a}$ are depicted in Table 2, results for hypotheses $5 \mathrm{~b}$ and $5 \mathrm{c}$ are provided in Table 4. TCKs and non-TCKs did not differ in their preference for transformational leadership. Hypothesis 5a therefore could not be confirmed.

Testing hypothesis $5 \mathrm{~b}$, which related to MPTs, in three cases we found a mediated relationship between TCK status and transformational leadership. Firstly, there was a negative indirect effect of TCK status on transformational leadership through flexibility. This finding implied that through flexibility, TCK status leads to a lower preference for transformational leadership. Secondly, through open-mindedness, TCK status had a positive indirect effect on transformational leadership. This meant that, through openmindedness, being a TCK had a positive effect on transformational leadership compared to not being a TCK. Thirdly, there was a negative indirect effect of TCK status on transformational leadership through emotional stability. Emotional stability mediated the relationship between TCK status and a preference for displaying transformational leadership in a negative way. Through emotional stability, TCK status had a negative impact on the preference to display transformational leadership. To conclude, mediation hypothesis $5 \mathrm{~b}$ could be confirmed partially for transformational leadership. All effect sizes for these indirect effects were small, as indicated by the standardised indirect effects.

The results from our analysis investigating whether TCK status affected a preference for transformational leadership indirectly through intercultural competences (hypothesis 5c) showed that none of the variables of the IRC mediated the relationship between TCK status and transformational leadership. Hypothesis $5 \mathrm{c}$ could thus not be confirmed. The effect sizes for these indirect effects were small or very small, as indicated by the standardised non-significant indirect effects. 
Table 4 Regression coefficients, standard errors, and model summary information for the parallel mediation models for transformational leadership

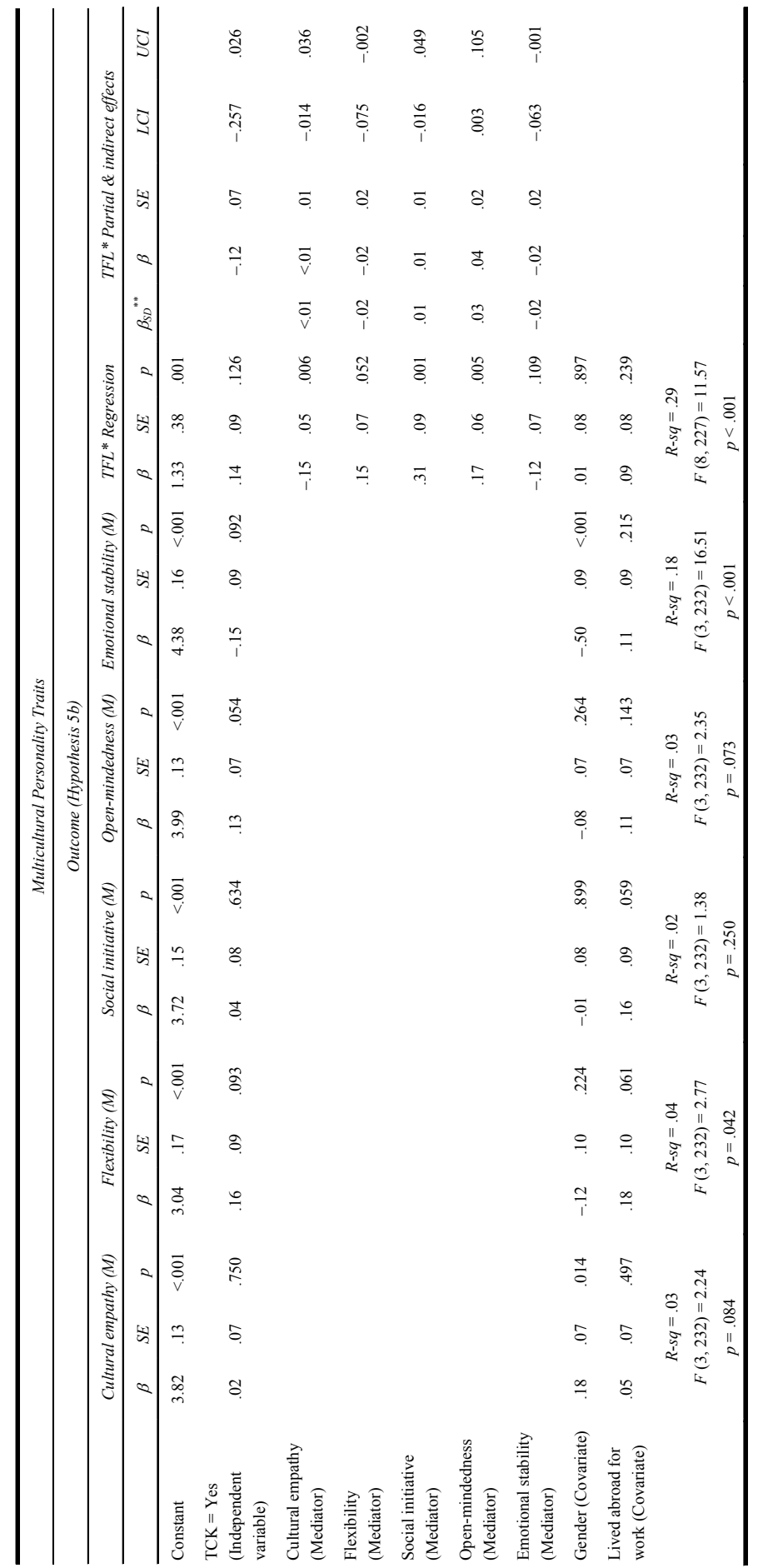


Table 4 Regression coefficients, standard errors, and model summary information for the parallel mediation models for transformational leadership (continued)

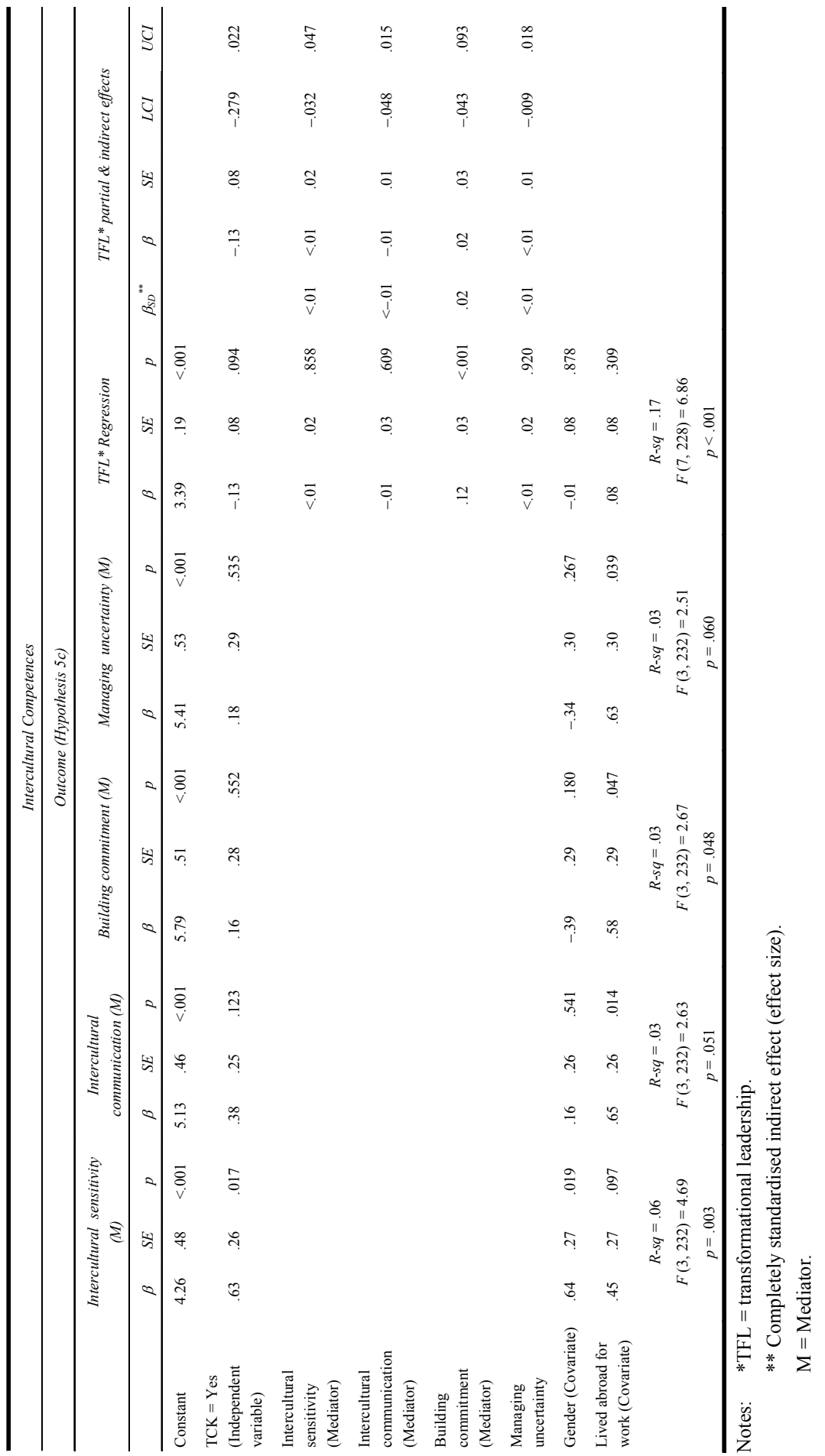




\section{Discussion}

The primary purpose of this study was to explore whether TCKs exhibit a stronger set of multicultural personality traits and intercultural competences than non-TCKs and to explore how these traits and competences relate to their own preference to show transformational leadership. Four important results were found: firstly, the differences between TCKs and non-TCKs with regard to multicultural personality traits and intercultural competences; secondly, relations between MPTs and ICs and styles of leadership; thirdly, direct relationships between TCK status and preferred styles of leadership; and finally, mediated relationships between TCK status and preferred styles of leadership.

Earlier research had found a positive correlation between being a TCK and openmindedness among teenagers (Dewaele and Van Oudenhoven, 2009). However, we could not generalise this result to the adult TCKs in the present sample. Regarding the multicultural personality traits of TCKs we can conclude that TCKs and non-TCKs show the same scores. Apparently, personality traits turn out to be more stable than earlier research indicated, within our respondents group. This would be in line with Roberts and DelVecchio (2006) who concluded that competences are generally considered to be more amenable than personality characteristics.

Regarding intercultural competences, TCKs scored higher on intercultural sensitivity than non-TCKs. No significant differences were found on the other three competences, however, namely: intercultural communication, building commitment, and managing uncertainty. The finding that TCKs score higher on intercultural sensitivity indicates that they seem capable of mapping the different cultural perspectives and of estimating the complexity of situations, usually being aware of more than one interpretation (Brinkmann and Van Weerdenburg, 2014). Early cross-cultural experiences of TCKs might have especially increased their cultural awareness and thus possibly recognising the value of diversity. The growing up among cultures other than their passport cultures may not lead to higher scores in intercultural communication, building commitment, and managing uncertainty. All these competences seem to be more rooted to changes in behaviour, than to changes in awareness.

Caligiuri and Tarique (2009) provided evidence that significant intercultural experiences positively impact one's flexibility and tolerance for ambiguity, the latter of which also was labelled as managing uncertainty by these authors. We could not repeat their results: In contrast, our results showed no significant difference when comparing TCKs to non-TCKs in terms of their flexibility and their managing uncertainty.

Most of the multicultural personality traits, except flexibility, as well as all of the four intercultural competences, were strongly related to a preference for the transformational leadership style. The focus of transformational leadership on the relationship part of leadership, with its elements of idealised influence, inspirational motivation, intellectual stimulation and individual consideration, fits these findings.

Though a direct relationship between being a TCK and preference for displaying a transformational leadership style was not confirmed in this study, this relationship seems to occur indirectly, namely through multicultural personality traits as mediators, both positively and negatively. TCKs, compared to non-TCKs, tend to show a higher preference for transformational leadership through their levels of open-mindedness. On the other hand, through their levels of flexibility and emotional stability, they tend to show a lower preference to use transformational leadership compared to non-TCKs. 
Even though these findings - particularly the positive and negative indirect effects in the absence of a direct one for transformational leadership - at first sight appear complex, they become clearer with some considerations. The results from the mediated regression analysis inform us that TCK status has an indirect effect on the preference for transformational leadership through three multicultural personality traits. First, TCKs score relatively high on the personality trait of flexibility, keeping their options open and being flexible. Yet, transformational leadership requires consistency in goal pursuit (Keeley, 1995). TCKs might want to keep their options open, instead of taking the lead and inspiring others towards one defined direction. This might explain that TCKs' higher flexibility compared to non-TCKs implies a somewhat weaker inclination to show transformational leadership.

Second, related to the trait of emotional stability, transformational leaders are expected to show stability, also implying high emotional stability. TCKs' relatively low emotional stability may therefore form a counterproductive multicultural personality trait for transformational leadership. On the other hand, thirdly, TCKs' open-mindedness might help them to empathise with followers' needs and thus may influence transformational leadership positively. Adding up these three effects, one could therefore conclude that TCKs' multicultural personality traits may imply a mixed but, in sum, overall positive effect on their preference for the transformational leadership style.

\section{Limitations of this study and implications for future research}

We recognise this study has some limitations. We had to control for gender differences and also for having lived abroad for work. This was necessary due to an unequal distribution of male and female participants among TCKs and non-TCKs and an unequal distribution of having lived abroad for work between both groups. Future research, with a more balanced design, might allow for a clearer evaluation of the effect of TCK status on the given outcome variables.

Another limitation of this study is that all measures were based on self-reports. People might overestimate their own desired behaviour. The responses, therefore, might be more in line with their (desired) self-image than with their actual behaviour. Not being able to distinguish among different types of TCKs (e.g., kids of expats, missionary kids) as well as having no exact information on the number of years having lived abroad in any period of the lifetimes of the respondents is another limitation of this study.

Moreover, we could not measure the degree to which TCKs' host culture(s) differed from their passport culture. Future research should therefore investigate whether this factor may influence the relationship between TCK experience and preferred leadership style. For example, how would growing up in a culture that values listening more than speaking influence one's preferred communication as a leader?

Furthermore, a research suggestion would be to investigate the degree of interaction of TCKs with the host culture(s), which may lead to new questions about the developed competences of TCKs. It would be interesting to investigate what factors the degree of interaction depends upon, such as different types of TCKs and the social constellation of the family. Side analyses in our dataset also indicated two factors that may influence a higher score on open-mindedness for TCKs, namely the number of countries lived in as a TCK, as well as having a higher education. 
Comparing TCK status versus living and working abroad as an adult could be an interesting topic for further research, to be able to explore the impact of TCK status relative to the effects of having lived and worked abroad. This refers to a more general issue regarding the importance of the TCK variable in the prediction of preferred shown leadership styles in comparison to other (culture-related) experiences. For such a study, data about the various types of TCKs would be helpful because one's culture-related experiences will vary for the different types of TCKs. For example, many military TCKs are used to living on a compound, and thus will have less direct contact with the hostculture(s) and therefore may impact their culture-related experiences as a TCK. Finally, this study used a $70 \%$ Dutch sample, which may add to the field of TCK research, since much TCK research has been based on American or Japanese samples. Future research might further expand the population of TCKs.

\section{Conclusion}

This study examined the relationships between multicultural personality traits and intercultural competences with a preference to show transformational leadership, comparing TCKs with non-TCKs. Looking for the impact of early life cross-cultural experiences on the development of multicultural personality traits and intercultural competences, our findings revealed that TCKs show more intercultural sensitivity compared to non-TCKs. One's TCK status affects one's preferred leadership style particularly through the trait of open-mindedness.

Based on these conclusions, in a world that seems to be increasingly in demand of global leaders with a transformational leadership style who do business across borders with intercultural ease, TCKs might turn out to be fitting candidates. They show a stronger preference for transformational leadership than non-TCKs, mediated by their open-mindedness. These findings imply that TCKs' open-mindedness and, possibly in a different way, their higher intercultural sensitivity influence their preference for transformational leadership rather than that this preference follows as a direct result of being a TCK or not.

\section{References}

Ang, S. and Koh, C. (2006) 'Personality correlates of the four-factor model of cultural intelligence', Group \& Organization Management, Vol. 31, No. 1, pp.100-123. http://dx.doi.org/10.1177/1059601105275267.

Anderson, P.H., Lawton, L., Rexeisen, R.J. and Hubbard, A.C. (2006) 'Short-term study abroad and intercultural sensitivity: a pilot study', International Journal of Intercultural Relations, Vol. 30, No. 4, pp.457-469. http://dx.doi.org/10.1016/j.ijintrel.2005.10.004.

Antonakis, J. (2001) The validity of the transformational, transactional, and Laissez-Faire Leadership model as measured by the Multifactor Leadership Questionnaire (MLQ 5X), PhD dissertation, Walden University, Ann Arbor, MI. https://doi.org/10.7903/cmr.704.

Bass, B.M., Avolio, B.J. and Atwater, L. (1996) 'The transformational and transactional leadership of men and women', Applied Psychology: An International Review, Vol. 45, No. 1, pp.5-34. http://dx.doi.org/10.1111/j.1464-0597.1996.tb00847.x.

Bird, A., Mendenhall, M., Stevens, M.J. and Oddou, G. (2010) 'Defining the content domain of intercultural competence for global leaders', Journal of Managerial Psychology, Vol. 25, No. 8, pp.810-828. https://doi.org/10.1108/02683941011089107. 
Bonebright, D. (2010) 'Adult third culture kids: HRD challenges and opportunities', Human Resource Development International, Vol. 13, No. 3, pp.351-359. https://doi.org/10.1080/ 13678861003746822.

Brinkmann, U. and Van Weerdenburg, O. (2014) Intercultural readiness: Four competences for working across cultures, Palgrave Macmillan, Hampshire. http://dx.doi.org/10.1057/ 9781137346988.

Bücker, J. and Poutsma, E. (2010) 'Global management competencies: a theoretical foundation', Journal of Managerial Psychology, Vol. 25, No. 8, pp.829-844. http://dx.doi.org/10.1108/ 02683941011089116.

Burns, J.M. (1978) Leadership, Harper \& Row, New York. http://dx.doi.org/10.1177/ 1742715005049347.

Caligiuri, P. and Tarique, I. (2009) 'Predicting effectiveness in global leadership activities', Journal of World Business, Vol. 44, No. 3, pp.336-346. http://dx.doi.org/10.1016/ j.jwb.2008.11.005.

Caligiuri, P. and Tarique, I. (2012) Dynamic Cross-Cultural Competencies and Global Leadership Effectiveness, Harper \& Row, New York. https://doi.org/10.1016/j.jwb.2012.01.014.

Caligiuri, P. and Tarique, I. (2016) 'Cultural agility and international assignees' effectiveness in cross-cultural interactions’, International Journal of Training \& Development, Vol. 20, No. 4 , pp.280-289. https://doi.org/10.1111/ijtd.12085.

Cason, R.M. (2015) 'Third Culture Kids': Migration Narratives on Belonging, Identity and Place, Unpublished PhD Thesis, Keele University, Staffordshire, UK.

Cohen, E. (2007) Leadership Without Borders, John Wiley \& Sons, New Jersey.

Cohen, J. (1988) Statistical Power Analysis for the Behavioral Sciences, Lawrence Earlbaum Associates, Hillsdale, NJ.

Cottrell, A.B. (2002) 'Educational and occupational choices of American adult third culture kids', in Ender, M. (Ed.): Military Brats and Other Global Nomads, Praeger, Westport, CN, pp.229-253. https://doi.org/10.1177/009182960403200421.

Cumberland, D.M., Herd, A., Alagaraja, M. and Kerrick, S.A. (2016) 'Assessment and development of global leadership competencies in the workplace: a review of literature', Advances in Developing Human Resources, Vol. 18, No. 3, pp.301-317. http://dx.doi.org/ $10.1177 / 1523422316645883$.

Dewaele, J-M. and Van Oudenhoven, J.P. (2009) 'The effect of multilingualism/multiculturalism on personality: no gain without pain for third culture kids?' International Journal of Multilingualism, Vol. 6, No. 4, pp.443-459. http://dx.doi.org/10.1080/14790710903039906.

Earley, P. and Ang, S. (2003) Cultural Intelligence: Individual Interactions Across Cultures, Stanford Business Books, Stanford, CA. http://dx.doi.org/10.1177/1523422316645883.

Engle, A.D., Mendenhall, M.E., Powers, R.L. and Stedham, Y. (2001) 'Conceptualizing the global competency cube: a transnational model of human resource', Journal of European Industrial Training, Vol. 25, pp.346-353. https://doi.org/10.1108/EUM0000000005836.

Fail, H., Thompson, J. and Walker, G. (2004) 'Belonging, identity and third culture kids: life histories of former international school students', Journal of Research in International Education, Vol. 3, No. 3, pp.319-338. http://dx.doi.org/10.1177/1475240904047358.

Fang, F., Schei, V. and Selart, M. (2018) 'Hype or hope? A new look at the research on cultural intelligence', International Journal of Intercultural Relations, Vol. 66, pp.148-171. https://doi.org/10.1016/j.ijintrel.2018.04.002.

Faul, F., Erdfelder, E., Lang, A.G. and Buchner, A. (2007) 'G* Power 3: a flexible statistical power analysis program for the social, behavioral, and biomedical sciences', Behavior Research Methods, Vol. 39, No. 2, pp.175-191. https://doi.org/10.3758/BF03193146.

Field, A. (Ed.) (2009) Discovering Statistics Using SPSS (and Sex and Drugs and Rock ' $n$ ' Roll), Sage, Los Angeles. 
Gerner, M.E. and Perry, F. (2000) 'Gender differences in cultural acceptance and career orientation among internationally mobile and non-internationally mobile adolescents', School Psychology Review, Vol. 29, No. 2, pp.267-283. https://doi.org/10.1016/0022-4405(92)90031-Y.

Hayes, A.F. (2012) PROCESS: A versatile computational tool for observed variable mediation, moderation, and conditional process modeling [White paper]. Available online at: http://www.afhayes.com/ public/process2012.pdf

Hayes, A.F. (2016) PROCESS: Process for SPSS and SAS (v2.16) [SPSS software extension]. Available online at: http://www.processmacro.org/download.html

Herfst, S.L., Van Oudenhoven, J.P. and Timmerman, M.E. (2008) 'Intercultural effectiveness training in three Western immigrant countries: a cross-cultural evaluation of critical incidents', International Journal of Intercultural Relations, Vol. 32, No. 1, pp.67-80. https://doi.org/10.1016/j.ijintrel.2007.10.001.

Hervey, E. (2009) 'Cultural transitions during childhood and adjustment to college', Journal of Psychology and Christianity, Vol. 28, No. 1, pp.3-12. http://doi.org/10.1037/E649172007001.

Keeley, M. (1995) 'The trouble with transformational leadership: toward a federalist ethic for organizations', Business Ethics Quarterly, Vol. 5, No. 1, pp.67-96. https://doi.org/ $10.2307 / 3857273$.

Lam, H. and Selmer, J. (2004) 'Are former 'third-culture kids" the ideal business expatriates?' Career Development International, Vol. 9, No. 2, pp.109-122. http://dx.doi.org/ $10.1108 / 13620430410526166$.

Langford, M. (1998) 'Global nomads, third culture kids and international schools', in Hayden, M.C. and Thompson, J.J. (Eds): International Education: Principles and Practice, Kogan Page, London, pp.28-43. https://doi.org/10.1177/0268580915571816.

Levy, O., Beechler, S., Taylor, S. and Boyacigiller, N.A. (2007) 'What we talk about when we talk about "global mindset": managerial cognition in multinational corporations', Journal of International Business Studies, Vol. 38, No. 2, pp.231-258. https://doi.org/10.1057/ palgrave.jibs.8400265.

Lyubovnikova, J., Napiersky, U. and Vlachopoulos, P. (2015) 'How are task reflexivity and intercultural sensitivity related to the academic performance of MBA students?' Studies in Higher Education, Vol. 40, pp.1694-1714. http://dx.doi.org/10.1080/03075079.2014.894016.

Matsumoto, D. and Hwang, H.C. (2013) 'Assessing cross-cultural competence: a review of available tests', Journal of Cross-Cultural Psychology, Vol. 44, pp.849-873. https://doi.org/10.1177/0022022113492891.

Matthewman, J. (2011) The Rise of the Global Nomad: How to Manage the New Professional in Order to Gain Recovery and Maximize Future Growth, Kogan Page, London.

Matveev, A.V. (2017) Intercultural Competence in Organizations: A Guide for Leaders, Educators and Team Players, Springer International Publishing, Cham. http://dx.doi.org/10.1007/978-3319-45701-7.

Matveev, A.V. and Merz, M.Y. (2014) 'Intercultural competence assessment: what are its key dimensions across assessment tools?' in Jackson, L., Meiring, D., van de Vijver, F., Idemudia, E. and Gabrenya, W. (Eds): Toward Sustainable Development Through Nurturing Diversity: Selected Papers from the Twenty-First Congress of the International Associate for CrossCultural Psychology, International Association for Cross-Cultural Psychology, Melbourne, FL, pp.141-153. http://dx.doi.org/10.1007/978-3-319-45701-7_5.

McCaig, N.M. (1994) 'Growing up with a world view: nomad children develop multicultural skills', Foreign Service Journal, Vol. 9, pp.32-39.

Miska, C., Stahl, G.K. and Mendenhall, M.E. (2013) 'Intercultural competencies as antecedents of responsible global leadership', European Journal of International Management, Vol. 7, pp.550-569. https://doi.org/10.1504/EJIM.2013.056477. 
Mol, S.T., Born, M.P. and Van der Molen, H. (2005) 'Developing criteria for expatriate effectiveness: time to jump off the adjustment bandwagon', International Journal of Intercultural Relations, Vol. 29, pp.339-353. https://doi.org/10.1016/j.ijintrel.2005.05.004.

Pedersen, P.J. (2010) 'Assessing intercultural effectiveness outcomes in a year-long study abroad program', International Journal of Intercultural Relations, Vol. 34, No. 1, pp.70-80. http://dx.doi.org/10.1016/j.ijintrel.2009.09.003.

Pollock, D.C. and Van Reken, R.E. (2009) Third Culture Kids: Growing Up Among Worlds, (Rev. ed.), Nicholas Brealey Pub, Boston.

Pollock, D.C., Van Reken, R.E. and Pollock, M.V. (2010) Third Culture Kids: The Experience of Growing Up Among Worlds: The Original, Classic Book on TCKs. (Rev. ed. 2017), Hachette, UK.

Remhof, S., Gunkel, M. and Schlägel, C. (2013) ,Working in the "global village": the influence of cultural intelligence on the intention to work abroad', German Journal of Human Resource Management/ Zeitschrift für Personalforschung, Vol. 27, No. 3, pp.224-250. http://dx.doi.org/10.1688/1862-0000_ZfP_2013_03_Remhof.

Roberts, B.W. and DelVecchio, W.F. (2006) 'The rank-order consistency of personality traits from childhood to old age: a quantitative review of longitudinal studies', Psychological Bulletin, Vol. 126, No. 1, pp.3-25. http://dx.doi.org/10.1037/0033-2909.126.1.3.

Rosen, R.T. (2000) Global Literacies: Lessons on Business Leadership and National Cultures: A Landmark Study of CEOs from 28 Countries, Simon \& Schuster, New York.

Ruben, B.D. (1989) 'The study of cross-cultural competence: traditions and contemporary issues', International Journal of Intercultural Relations, Vol. 13, pp.229-240. https://doi.org/10.1016/ 0147-1767(89)90011-4.

Ruben, B.D. and Kealey, D.J. (1979) 'Behavioral assessment of communication competency and the prediction of cross-cultural adaptation', International Journal of Intercultural Relations, Vol. 3, pp.15-47. https://doi.org/10.1016/0147-1767(79)90045-2.

Selmer, J. and Lam, H. (2004) “"Third-culture kids” future business expatriates?' Personnel Review, Vol. 33, No. 4, pp.430-445. https://doi.org/10.1108/00483480410539506.

Schlaegel, C., Richter, N.F. and Taras, V. (2017) 'Cultural intelligence and work-related outcomes: a meta-analytic review', Academy of Management Proceedings. doi:10.5465/ambpp.2017.229.

Smith, M.B. (1966) 'Explorations in competence: a study of Peace Corps teachers in Ghana', American Psychologists, Vol. 21, pp.555-566. http://dx.doi.org/10.1037/h0023607.

Spitzberg, B.H. and Changnon, G. (2009) 'Conceptualizing intercultural competence', in Deardorff, D.K. (Ed.): The SAGE Handbook of Intercultural Competence, SAGE, Thousand Oaks, pp.2-52. http://dx.doi.org/10.4135/9781483346267.n13.

Thomas, D.C. and Fitzsimmons, S.R. (2008) 'Cross-cultural skills and abilities: from communication competence to cultural intelligence', in Smith, P.M., Peterson, M.F. and Thomas, D.C. (Eds): The Handbook of Cross-Cultural Management Research, SAGE Publications, pp.201-215. http://dx.doi.org/10.4135/9781412982764.

Useem, R.H. and Downie, R.D. (1976) 'Third-Culture Kids', in Bell-Villada, G. and Sichel, N. (Eds): Writing Out of Limbo: International Childhoods, Third Culture Kids and Global Nomads, Cambridge Scholars Publishing, Newcastle upon Tyne, pp.103-105. https://doi.org/10.1177/0268580915571816.

Useem, J., Useem, R. and Donoghue, J. (1963) 'Men in the middle of the third culture: the roles of American and Non-Western people in cross-cultural administration', Human Organization, Vol. 22, No. 3, pp.169-179. http://dx.doi.org/10.17730/humo.22.3.547n4438kk6733.

Van Bakel, M.S. (2012) In Touch with the Dutch. A Longitudinal Study of the Impact of a Local Host on the Success of the Expatriate Assignment, Ipskamp Drukkers, Nijmegen, The Netherlands. 
Van Bakel, M.S., Gerritsen, M. and Van Oudenhoven, J.P. (2014) 'Impact of a local host on the intercultural competence of expatriates', International Journal of Human Resource Management, Vol. 25, No. 14, pp.2050-2067. http://dx.doi.org/10.1080/ 09585192.2013.870292.

Van der Poel, M.H. (2016) 'When does study abroad foster intercultural competence development? A study in search of the conditions', European Journal of Cross-Cultural Competence and Management, Vol. 4, pp.168-185. https://doi.org/10.1504/EJCCM.2017.083841.

Van der Zee, K.I. and Brinkmann, U. (2004) 'Construct validity evidence for the intercultural readiness check against the multicultural personality questionnaire', International Journal of Selection and Assessment, Vol. 12, No. 3, pp.285-290. http://dx.doi.org/10.1111/j.0965075X.2004.283_1.X.

Van der Zee, K.I. and Van Oudenhoven, J.P. (2000) 'The multicultural personality questionnaire: a multidimensional instrument of multicultural effectiveness', European Journal of Personality, Vol. 14, No. 4, pp.291-309. http://dx.doi.org/10.1002/1099-0984(200007/ 08)14:4\%3c291::aid-per377\%3e3.0.co;2-6.

Van der Zee, K.I., Van Oudenhoven, J.P., Ponterotto J.G. and Fietzer, A.W. (2013) 'Multicultural personality questionnaire: development of a short form', Journal of Personality Assessment, Vol. 95, No. 1, pp.118-124. http://dx.doi.org/10.1080/00223891.2012.718302.

Van Oudenhoven, J.P. and Van der Zee, K.I. (2002) 'Predicting multicultural effectiveness of international students: the multicultural personality questionnaire', Journal of Intercultural Relations, Vol. 26, pp.679-694. https://doi.org/10.1016/S0147-1767(02)00041-X.

Van Reken, R. and Bethel, P. (2005) 'Third culture kids: prototypes for understanding other cross-cultural kids', Intercultural Management Quarterly, Vol. 6, No. 4, pp.3-9. http://dx.doi.org/10.1016/B978-0-08-044894-7.01473-1.

Van Woerkom, M. and De Reuver, R.S.M. (2009) 'Predicting excellent management performance in an intercultural context: a study of the influence of multicultural personality on transformational leadership and performance', The International Journal of Human Resource Management, Vol. 20, No. 10, pp.2013-2029. http://dx.doi.org/10.1080/09585190903175589.

Verghese, T. and D'Netto, B. (2011) 'Cultural intelligence and openness: essential elements of effective global leadership', International Review of Business Research Papers, Vol. 7, No. 1, pp.191-200. http://hdl.handle.net/20.500.11937/4147.

Walters, K.A. and Auton-Cuff, F.P. (2009) 'A story to tell: the identity development of women growing up as third culture kids', Mental Health, Religion \& Culture, Vol. 12, No. 7, pp.755-772. http://dx.doi.org/10.1080/13674670903029153.

Williams, T.R. (2005) 'Exploring the impact of study abroad on students' intercultural communication skills: adaptability and sensitivity', Journal of Studies in International Education, Vol. 9, No. 4, pp.356-371. http://dx.doi.org/10.1177/1028315305277681.

\section{Note}

1 It is important to point to the existence of statistical indices such as point-biserial correlation coefficients, which are used when one variable (e.g., TCK status) is naturally (versus artificially) dichotomous and the other is continuous. The point-biserial correlation coefficient is mathematically equivalent to the Pearson (product moment) correlation coefficient. This implies that when one continuously measured variable is correlated with a dichotomous variable, then $r_{\mathrm{XY}}=r_{\mathrm{pb}}$. 
Appendix 1: Table of measures: Multicultural Personality Questionnaire, Intercultural Readiness Check and Multifactor Leadership Questionnaire, including alpha reliabilities, response scales and example items

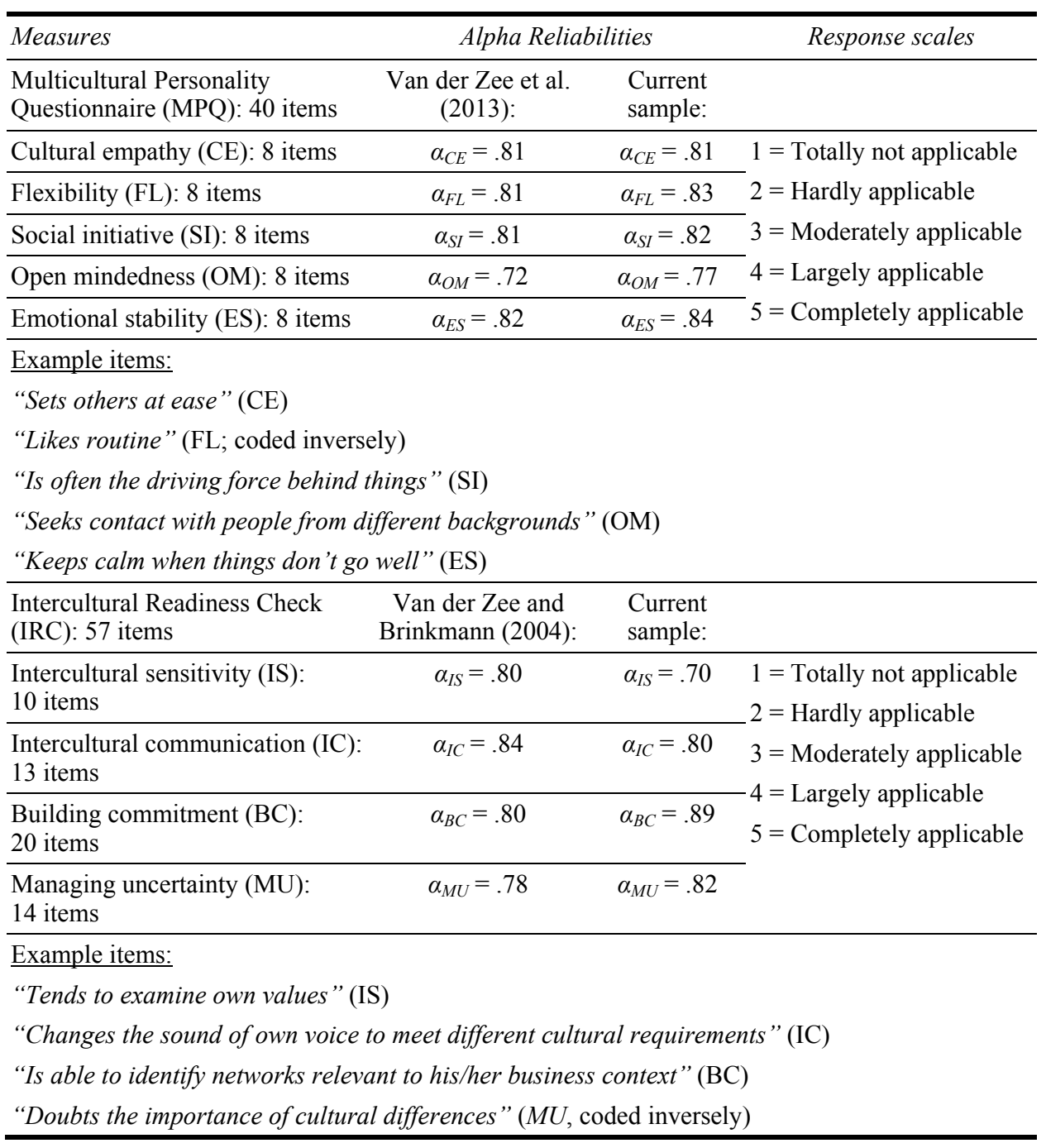


Appendix 1: Table of measures: Multicultural Personality Questionnaire, Intercultural Readiness Check and Multifactor Leadership Questionnaire, including alpha reliabilities, response scales and example items (continued)

\begin{tabular}{|c|c|c|c|}
\hline Measures & \multicolumn{2}{|c|}{ Alpha Reliabilities } & Response scales \\
\hline $\begin{array}{l}\text { Multifactor Leadership } \\
\text { Questionnaire (MLQ): } 28 \text { items }\end{array}$ & $\begin{array}{l}\text { Antonakis } \\
\text { (2001): }\end{array}$ & $\begin{array}{l}\text { Current } \\
\text { sample: }\end{array}$ & \\
\hline $\begin{array}{l}\text { Laissez faire leadership (LFL): } \\
4 \text { items }\end{array}$ & $\alpha_{L F L}>.70$ & $\alpha_{L F L}=.62$ & $\begin{array}{l}1=\text { Not at all } \\
2=\text { Once a while }\end{array}$ \\
\hline $\begin{array}{l}\text { Transactional leadership (TAL): } \\
9 \text { items }\end{array}$ & $\alpha_{T A L}>.70$ & $\alpha_{T A L}=.52$ & $3=$ Sometimes \\
\hline $\begin{array}{l}\text { Transformational leadership (TFL): } \\
15 \text { items }\end{array}$ & $\alpha_{T L F}>.70$ & $\alpha_{T L F}=.92$ & $5=$ Frequently, if not always \\
\hline
\end{tabular}

Example items:

"I undertake action only when needed" (LF)

"For excellent work, I will agree to a special bonus" (TA)

"I inspire people to achieve more than they would have achieved without me" (TFL) 